\title{
Infiltrate Object Extraction in X-ray Image by using Math-Morphology Method and Feature Region Analysis
}

\author{
Julius Santony ${ }^{\# 1}$ and Jufriadif $\mathrm{Na}^{\prime} \mathrm{am}^{\# 2}$ \\ \# Computer Science Faculty, Putra Indonesia University, Padang, 25221, Indonesia \\ E-mail: ${ }^{1}$ juliussantony@yahoo.co.id; ${ }^{2}$ jufriadifnaam@gmail.com
}

\begin{abstract}
Infiltrate is often called as pulmonary vlek for there are white spotteds on the lung. White spotted could be in form of liquid, condensation, or uncircumcised. The liquid is emerge from blood or suppuration. To detect the existence of infiltrate on the lung, it could be done by doing X-ray Thorax checkup. To observe the infiltrate on $x$-ray thorax image is unable to be seen by every people, but it is done by experts such as radiologists or the pulmonary experts by doing conscientious research. The research was done by extracting the infiltrate object on x-ray thorax image of tuberculosis patient to clarify the object. The research stage that was done on $x$-ray thorax image is by detecting the object with segmentation morphology process which consist of dilation and erosion morphology, and side detection by decreasing the value of dilation and erosion morphology. The next stage is extracting the infiltrate object by using binarization and feature region analysis to ommit the unspotted part and determine the infiltrate object from the amount of existing objects. The result of infiltrate object extraction, then, is being calculated for both number and width of each side of lung by using feature region analysis. The result indicates that infiltrate object extraction is able to show an image with the explicit infiltrate object. The result trials of $40 \mathrm{x}$-ray thorax image on tuberculosis patients proved that the well-extracted images are able to be determined whether on its position, total, and width of infiltrates on lung. The trials of 2 x-ray thorax image on healthy patients are also done as comparisons, and the result indicates that there is no infiltrate objects on both sides of lung.
\end{abstract}

Keywords - infiltrate; tuberculosis; x-ray thorax; extracting; morphology; feature region

\section{INTRODUCTION}

The particular organ which attacked by toberculosis is the lung, which is known as lung tuberculosis [1]. Early detection is urgently needed during the treatment on TB lung patient. It is done in order to prevent the physic derivation. The early detection on the abnormal organ is urgently needed since if it is known what is the major causer of an illness, then it will be easy to do an appropriate treatment [2]. To detect the tuberculosis on the lung is done by checking the result of x-ray thorax image [3]. It is preceed digitally, so the image process is able to be used to analyze the object among them is infiltrate.

X-ray thorax image is lung of tuberculosis patient which have infiltrates on it will be measured by the expert doctors.

Determining someone who has a lung disorder from x-ray thorax image, there are still some problems that occur in : (a) It could occur some different interpretations between radiologists and the expert of pulmonary. It is even possible that there are different interpretations between pulmonary doctors [4]; (b) It needs a long time to decide someone have lung disorder if it is seen from x-ray thorax image. Usually, it needs about one day to discover that someone has a lung disorder. After printing the result of x-ray thorax image, it needs to be checked by the radiologist. Then, it's continued to be seen by the pulmonary doctor and being decided whether there is a lung disorder or not[5].

In this research there will be an extraction for one of the abnormality of the lungs, that is the object infiltrate extraction in x-ray thorax image of tuberculosis patient, so that the infiltrate object can be seen clearly and immediately.it also can equalize the interpretation between the radiologists and pulmonary expert, or among the pulmonary expert. From the result of the infiltrate object extraction then the amount and the size of the infiltrate in the right lung and the left lung will be known through the region analysis feature.

For infiltrate object extraction, the process that will be conducted is started by segmenting the image using morphology dilation and morphology erosion method. The combination of dilation morphology and erosion morphology method will produce the gray scale image and it can detect the side of the entire object in the lungs [8]. The gray scale image next will be transformed to binary image. From the binary image the object can be extracted and detected as infiltrate through the region analysis feature. The size can be known after the extraction of the infiltrate. 


\section{RESEARCH METHOD}

To build the extraction systems of infiltrates object on $\mathrm{x}$-ray image of the thorax tuberculosis patients required a research method that consists of stages are carried out, as can be seen in Figure 1.

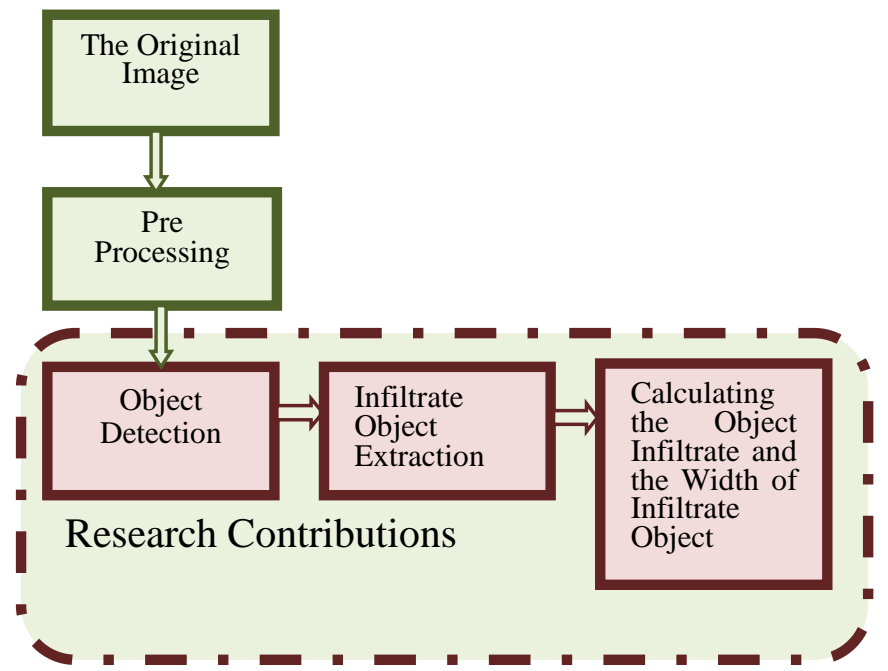

Fig 1 Research Stages

\section{RESULT AND DISCUSSION}

\section{A. Original Image}

The entire document should be in Times New Roman or Times font. Type 3 fonts must not be used. Other font types may be used if needed for special purposes. Recommended font sizes are shown in Table 1.

The original image is used as the data input. The image is the $\mathrm{x}$-ray thorax image in form of $* . \mathrm{Jpg}$. All the test images used are the grayscale x-ray thorax image with $1760 \times 1760$ pixel, to standardized the dimension of the test image. There are $42 \mathrm{x}$-ray thorax images collected from adult patient with 2 healthy patients and 40 tuberculosis patient. There are the infiltrate objects known by expert in $40 \mathrm{x}$-ray thorax images of tuberculosis patient. The position of the infiltrate of 10 images from 40 images has been decided before the infiltrate extraction process conduct, and another 30 images after the infiltrate extraction object conducted.

\section{B. Pre Processing by Cropping}

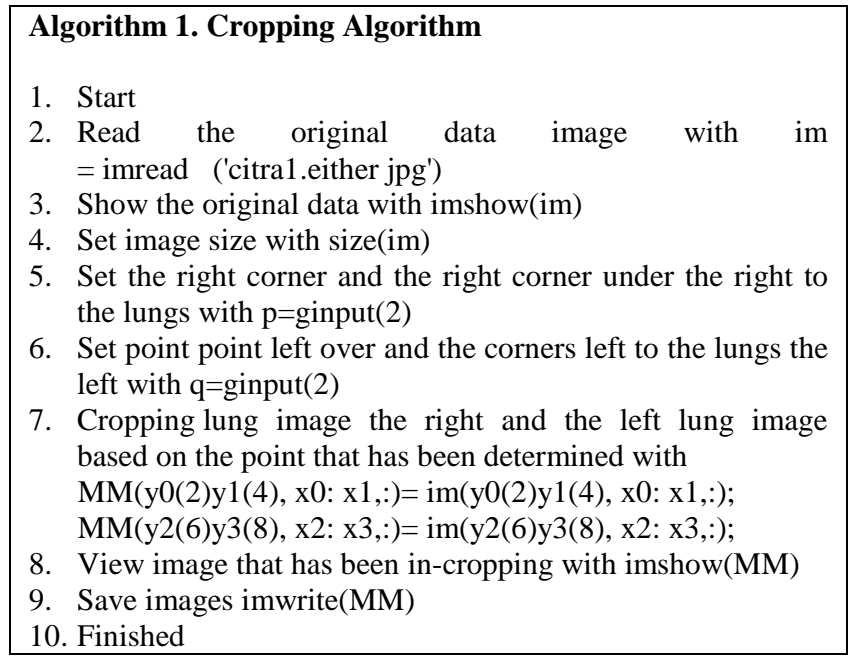

Result :
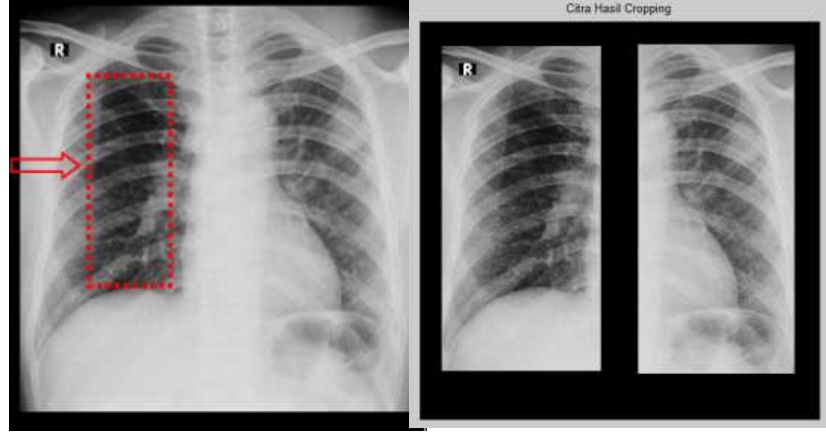

Fig 2 Original Image and the Result Image of Cropping Execution

\section{Object Detection with Morphology Math}

Methods of mathematical morphology with morphological dilation, morphological erosion and reduction of morphological dilation and erosion morphology process is capable of detecting objects that exist on the x-ray image of the thorax, including the infiltrates object (Figure 3).

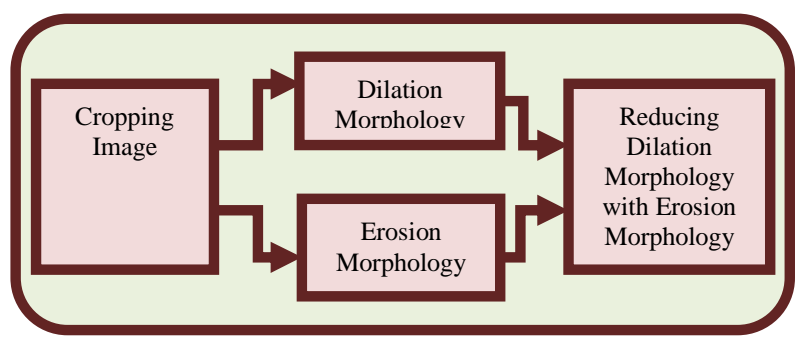

Fig 3 Process Diagram of Object Detection

\section{1) Dilation Morphology}

Algorithm 2. Dilation Morphology Algorithm
1. Start
2. Read image cropping result with I = imread ('citra1_1c.jpg ' )
3. Elegantly cropping with imshow(I)
4. Set a side for the dilation morphology image
with se=strel( 'ball',7,7)
5. Do the dilation morphology with I2 = imdilate (I,se)
6. View result dilation morphology with imshow (I2)
7. Save the product image dilation morphology
with imwrite(I2)
8. Finished

Result:

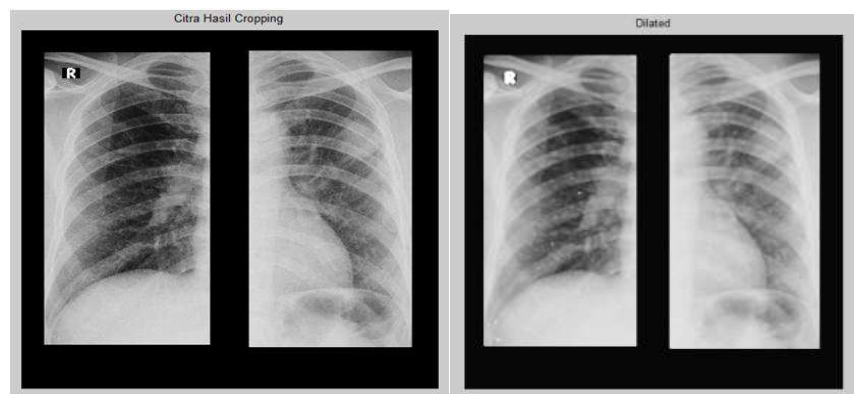

Fig 4 The image result of Cropping and Dilation Morphology 


\section{2) Erosion Morphology}

Algorithm 3. Erosion Morphology Algorithm
1. Start
2. Read the image result of cropping with I = Imread
('citra1_1c.jpg ')
3. Elegantly cropping with imshow(I)
4. Specify size for the erosion morphology image
with se=strel( 'ball',7,7
5. Do the erosion morphology by I3 = imerode(I,se)
6. View result erosion morphology by imshow(I3)
7. Save result image process erosion morphology
by imwrite(I3)
8. Finished

Result :

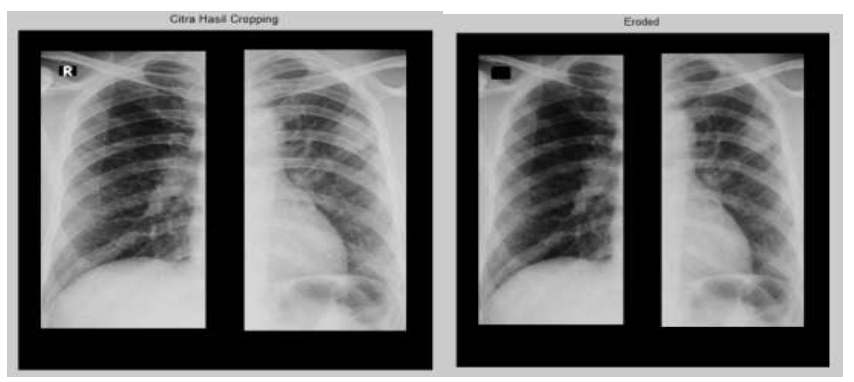

Fig 5 Original image and the Result Image of Erosion Morphology

3) The Decrement of Dilation Morphology with Erosion Morphology (Edge Objects Detection)

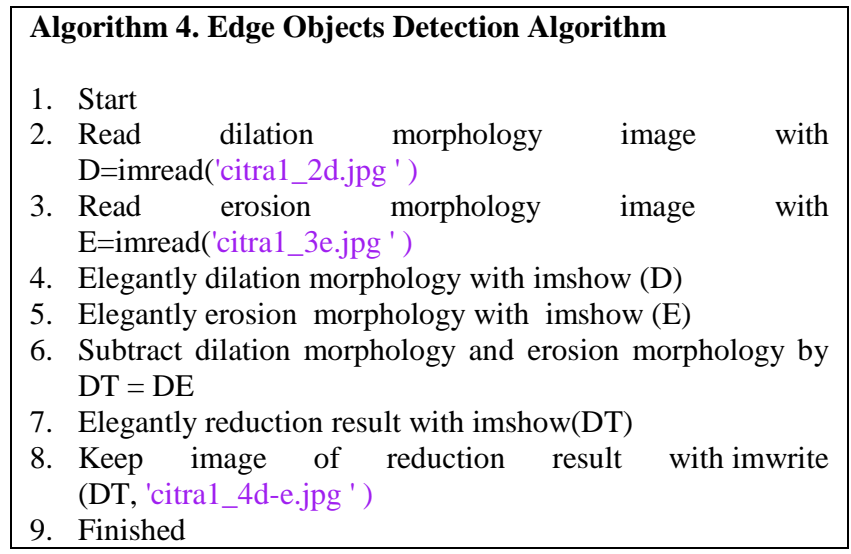

Result :

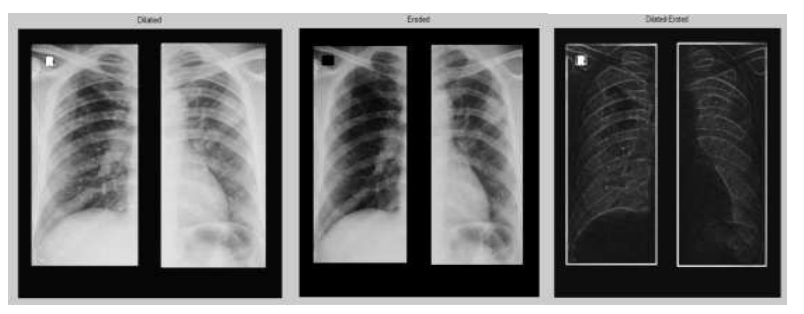

Fig 6 Original Image in form of Side Object Detection on Lung

\section{Infiltrate Object Extraction}

Extraction step of infiltrates object consist of binary process, calculating the area of each object, object removal which has an area that is larger than the object spots and ends with the extraction of infiltrates (Figure 7).

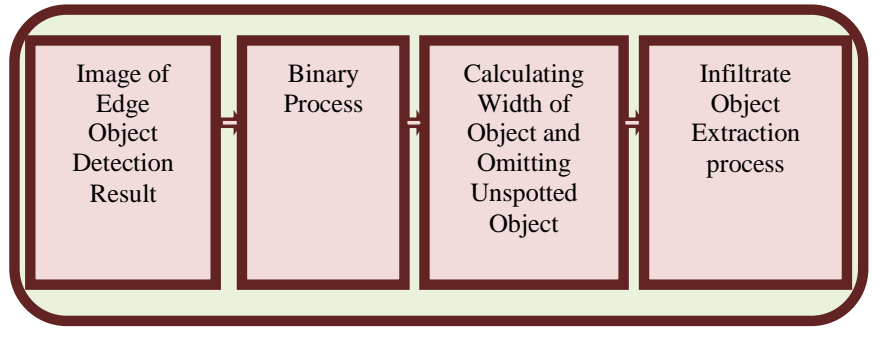

Figure 7 Process Diagram of Infiltrate Object Extraction

1) Binary Process

Algorithm 5. Binary Algorithm
1. Start
2. Read image of edge object detection result by
DT=imread('citra1_4d-e.jpg ')
3. Elegantly edge object detection result with imshow(DT)
4. From edge object detection result do change their grayscale
image to binary image with the son of = DT $>42$
5. Elegantly binary result with imshow(BIN)
6. Keep image of binary result with imwrite
(bin,'citra1_5bin.jpg ')
7. Finished

Result :

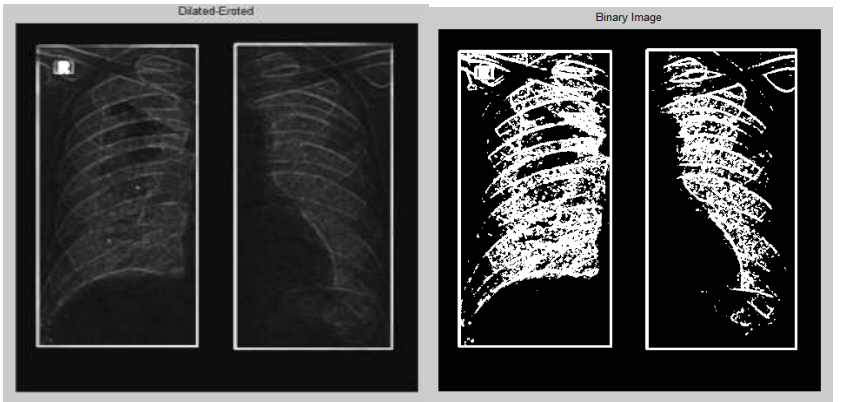

Fig 8 Original Image of Edge Objects Detection Result on Lung and Binary Image

2) Calculating Width of Object and Omitting Unspotted Object

Algorithm 6. Tracking Area and eliminate area algorithm

1. Start

2. Read the image of binary result with BIN=imread('citra1_5bin.jpg ')

3. Removed noise that is not the object in an area with (bwconncomp('imagebiner'")

4. Set area objects that are identified as spot (Regionprops ( imagebiner,'Area'))

5. If index of each area $<280$, do giving label and input in the areas that are identified spot with (ismember(labelmatriz(imagebiner),index)

6. View result image of each group area Buried image grouping result areas

7. Keep image that are identified as spot with imwrite(AINF,'citra1_6ainf.jpg ')

8. Do the dilation morphology to clarify area objects that are identified as spot with $\mathrm{se}=$ strel('disk',2); I4=imdilate(AINF,se)

9. Elegantly result that area the object was already made clear with imshow(I4)

10. Save result image grouping areas that are identified As spots that have been made clear with imwrite (BINF,'citra1_7binf.jpg ')

11. Finished 
Result :
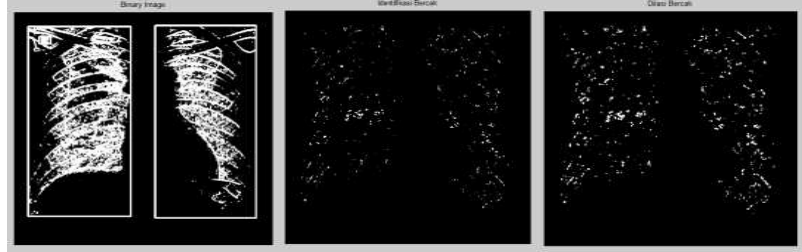

Fig 9 Original Image of Binary Result and Image Result of Spotted Identification

\section{3) Infiltrate Object Extraction}

\section{Algorithm 7. Mapping Algorithma}

1. Start

2. Read the image grouping result areas that are identified as spots that have been made clear with BINF=imread('citra1_7binf.jpg ')

3. $\mathrm{INF}=\mathrm{BINF}$

4. Set of each area objects and address list and pixels index passes, $\quad(\mathrm{s} 1=$ regionprops $(\mathrm{BINF}, \quad$ 'Area', 'pixellist', 'pixelidxlist');

5. Set image size and number of areas $(\mathrm{M}, \mathrm{N}]=$ size (BINF); [K,L)size (s1);

6. Check position each object to $\mathrm{k}$, Calculate the pixel every $\mathrm{k}(\mathrm{AA}(\mathrm{s} 1(\mathrm{k}, 1)$. PixelList;Count size each pixel k ([HH,LI) $=\operatorname{size}(\mathrm{AA})$;

Set 0 for the number of Sum=pixel k (double $(0)$;

7. Check area next $(k=k+1)$. Calculate The total value pixel $k$ is divided into a pixel completely $(\mathrm{Av}=\mathrm{Sum} / \mathrm{KK})$; If $\mathrm{Av}>$ 53, removing object (not the object was seeking).

INF (s1(k).PixelIdxList) $=0$

Sum values pixel resolution that has been identified as an object infiltrate every $\mathrm{k}$,

8. View the final result (objects infiltrat who sought) with imshow(INF)

9. Save image area result object infiltrate with imwrite (INF,'citra1_8inf.jpg ')

10. Finished

\section{Algorithm 8. Calculating the Object Infiltrate and the}

\section{Width of Infiltrate Object algorithm}

1. Start

2. Read image object result infiltrate with INF $=$ imread ('citra1_8inf.jpg ')

3. Set of each area objects and address list and unthinkable index pixel screen res.-pixel screen res., (s2 = regionprops ( BW , 'Area', ' pixellist', 'pixelidxlist');

4. Specify size $s 2,[K, L]=$ size(s2);

5. $\mathrm{Left}=0 ;$;ight $=0$;

6. Jright $=0 ;$ Jleft $=0$;

7. Check position each object infiltrate to $k$,

Count the pixel every $\mathrm{k}$ values if $\mathrm{AA}(\mathrm{I}, 1)>=\mathrm{x} 0$ and $\mathrm{AA}(\mathrm{I}, 1)<=\mathrm{x} 1$, do $\operatorname{rightk}(\mathrm{k})=\mathrm{s} 2(\mathrm{k})$. Area; right $=$ right + rightk $(\mathrm{k}) ; \mathrm{Jright}=\mathrm{Jright}+1$;

If not, do blue $(\mathrm{k})=\mathrm{s} 2(\mathrm{k})$. Area; left=left+blue (k);Jleft=Jleft+1;

8. View Right result, Jright, left and Jleft, disp(['Area Right: ', num2str(right)]); disp((No. 'Area Left : ', num2str(left)]); disp(['Number of Infiltrate Right: ', num2str(Jright)]); disp(['Number of Infiltrate Left : ', num2str(Jleft)]);

9. Finished
Result :

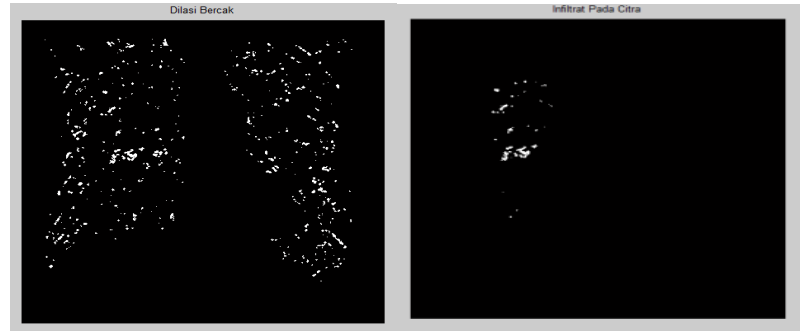

Fig 10 Image Result of Spotted Dilation Process and Image Result of Infiltrate Object

\section{E. Calculating the Object Infiltrate and the Width of Infiltrate Object}

The number and wide area of infiltrate objects can be counted by using the feature analysis region. Area of infiltrates object which have been detected can be quantified both for the lungs or the right and left lung. Based on the number of infiltrates the each are can be determined, so it can produce extensive infiltrates in the right lung, the left lung and the lung as a whole (Figure 11).

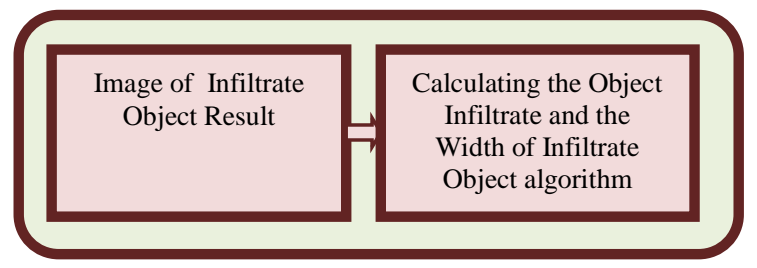

Fig 11. Process Calculating the Object Infiltrate and the Width of Infiltrate Object

After the 8 algorithm process there are 36 infiltrate in the right lung and no infiltrate in the left lung detected. There are 6614 pixel in 36 infiltrate detected. The computed radiographytool used produce $5 \mathrm{pixel} / \mathrm{mm} \mathrm{x}$-ray thorax image. 1 pixel equals $0,2 \mathrm{~mm}$. 1 pixel $^{2}$ equals $0,04 \mathrm{~mm}^{2}$ for the size. From the determination there are the calculations as follows:

TABLE I

RESUlt OF THE TOTAL INFILTRATE AND THE WIDTH OF INFILTRATE OBJECT

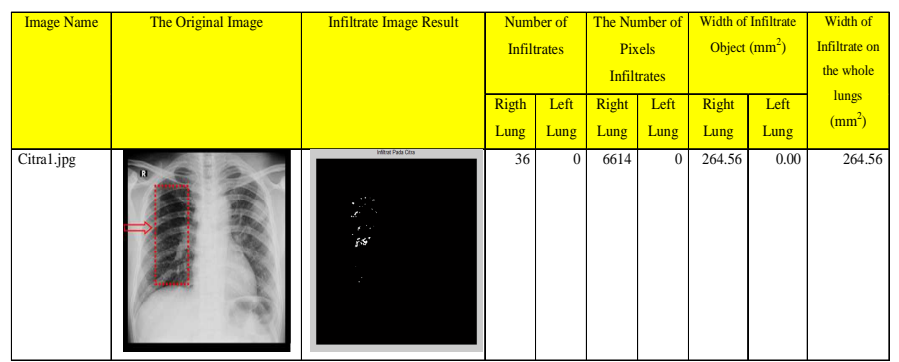

\section{F. X-ray Thorax Image From Healthy-Patient}

The Change of image from the original image to the image that shows only the infiltrates object to the healthy patients can be seen in Figure 12 . 


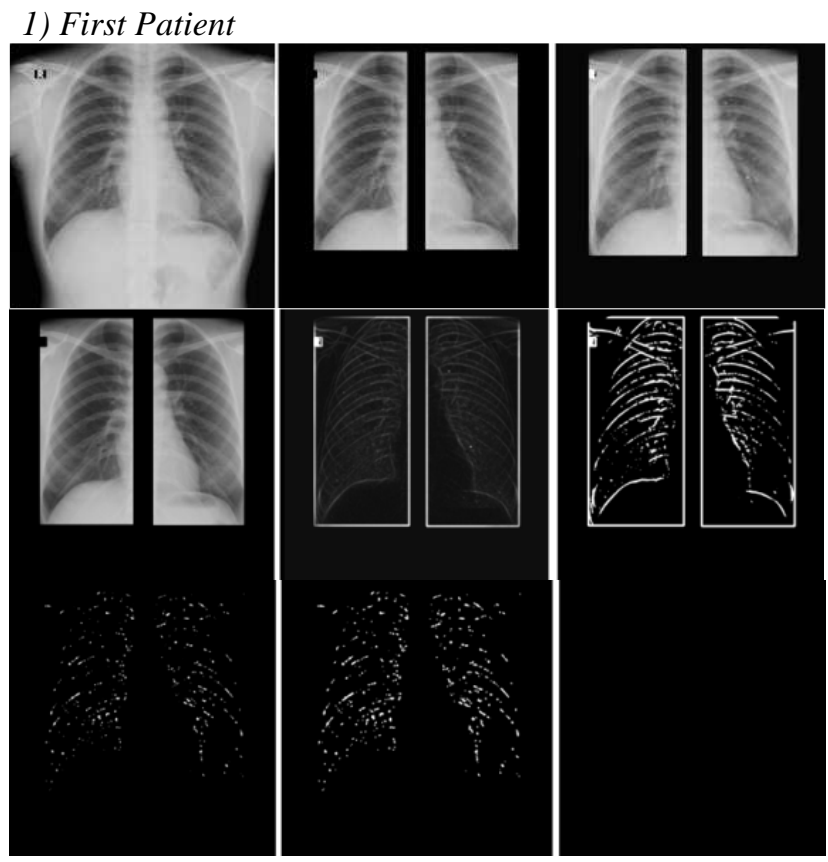

2) Second Patient

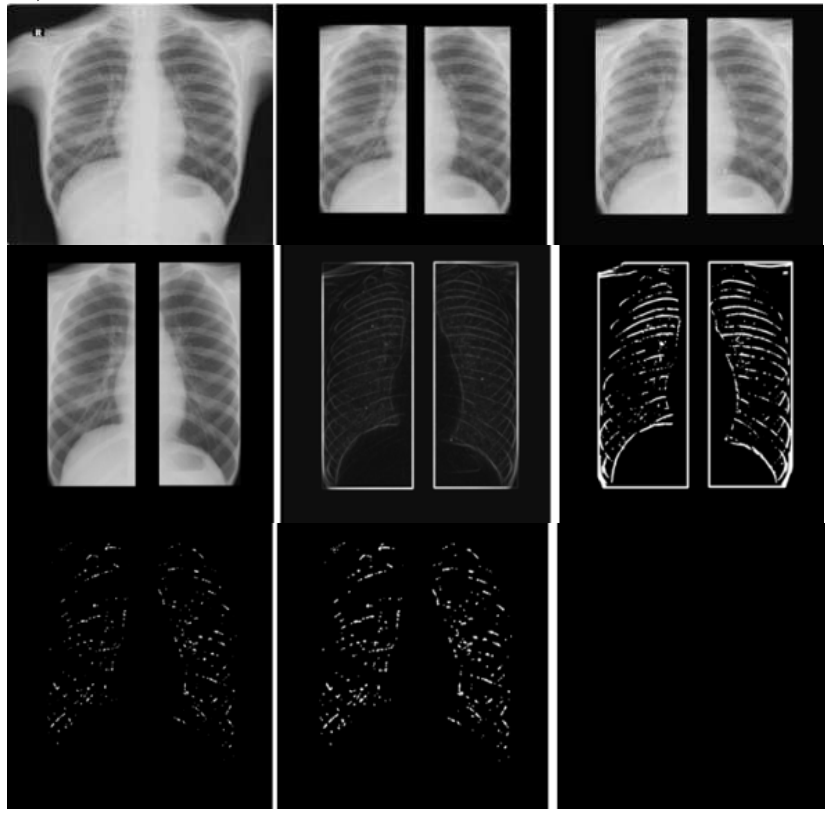

Fig 12 .The Changing of Original Object into the Result Infiltrate Object Image on the Healthy-Patient

\section{G. X-ray thorax image from tuberculosis patient}

The Change of image from the original image to the image that shows only the object infiltrates to patients with tuberculosis can be seen in Figure 13.
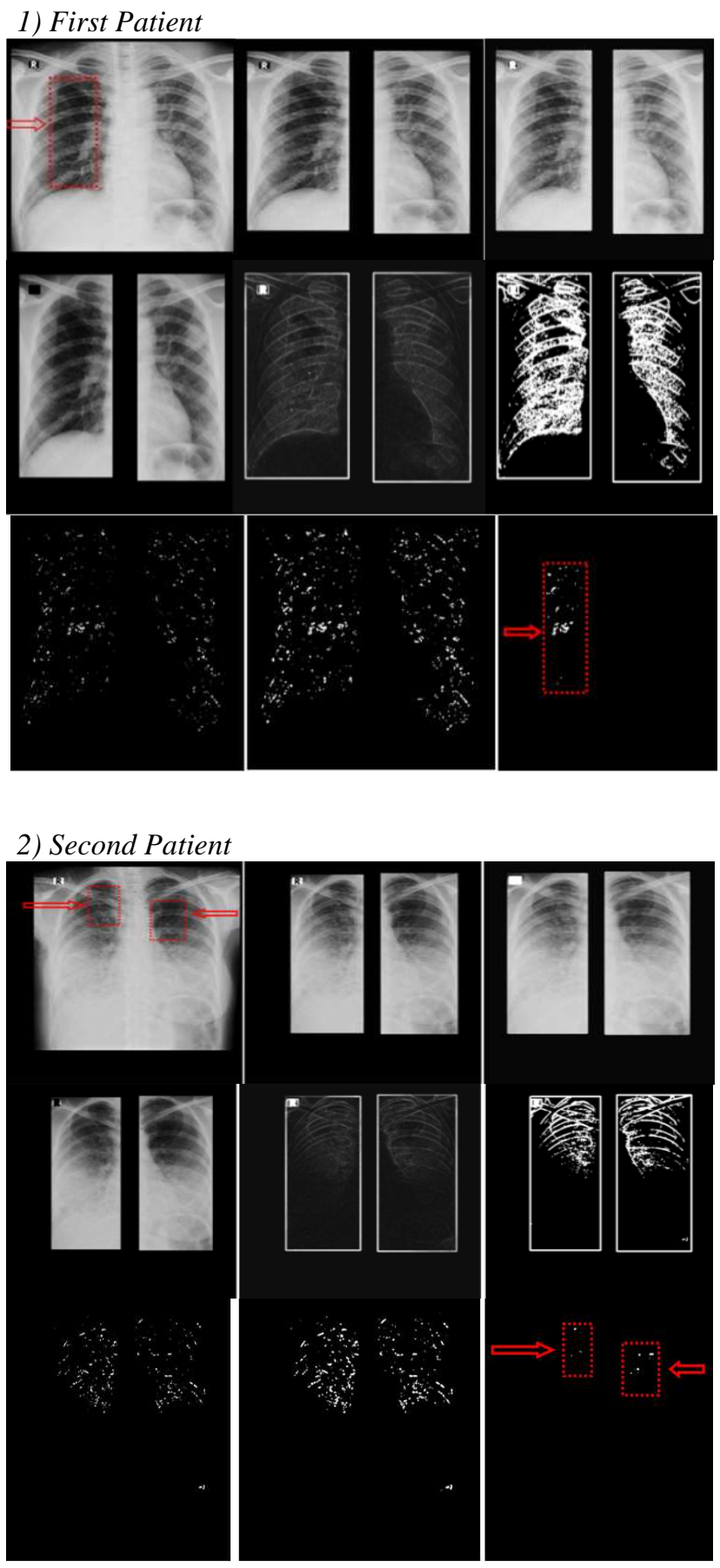

Fig 13 The Changing of Original Object into the Result Infiltrate Object Image on the Second Tuberculosis-Patient

\section{H. Number of Objects Infiltrate and Width of Infiltrate Object}

\section{1) Healthy Patient}

There were no infiltrates in the right lung and the left lung for both healthy patients. 
TABLE II

NuMBER OF OBJECTS INFILTRATE AND WIDTH OF INFILTRATE OBJECT

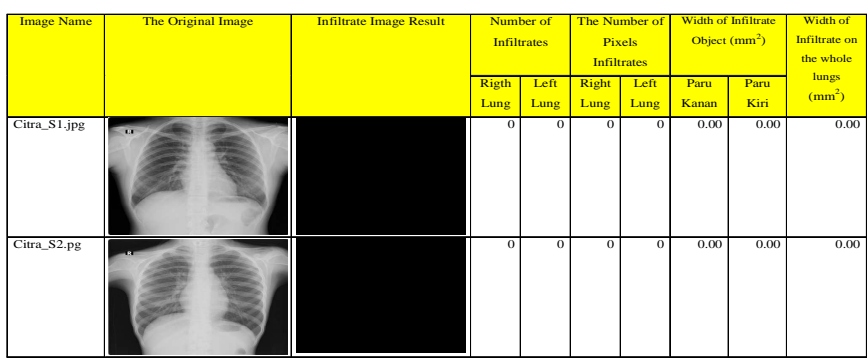

\section{2) Tuberculosis patient}

Number of Infiltrate Objects contained on right lung was 36 spots, while no infiltrates object in the left lung. Of the 36 spots the obtained results in a pixel number of 6614 pixels. Based on the provisions the tools used computed radiography, one pixel is $0.2 \mathrm{~mm}$. To the extent one pixel ${ }^{2}=$ $0.2 \mathrm{~mm} \times 0.2 \mathrm{~mm}$, so that one pixel $^{2}$ value is equal to 0.04 $\mathrm{mm}^{2}$. From these provisions, it can produce the same calculations as Table 3.

TABLE III

NuMBER OF OBJeCtS INFILTRATE AND WIDTH OF INFILTRATE OBJECT

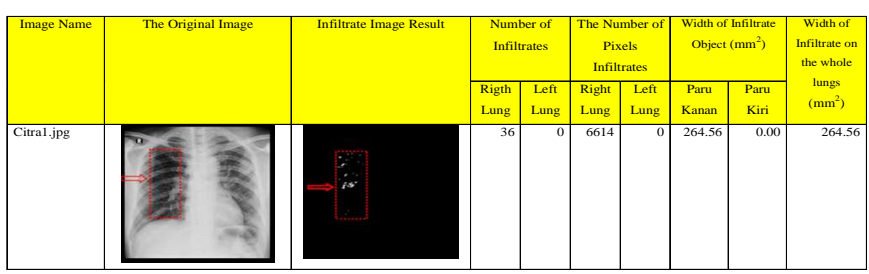

\section{CONCLUSIONS}

Based on the examination to the built algorithm it can be generalized that the infiltrate object extraction in $\mathrm{x}$-ray thorax image using morphology method and region feature analysis produced a clear infiltrate object image. The position of infiltrate gets by pulmonary expert match the position of infiltrate from the algorithm implementation. In the case of healthy patient, from 2 test image, the algorithm implementation result matched the analysis of the pulmonary expert - there is no infiltrate in $\mathrm{x}$-ray thorax image. In the test of $40 \mathrm{x}$-ray thorax images of tuberculosis patient where the position of the infiltrate of 10 images is already decided before the extraction process and 30 more after the extraction process, the position of the infiltrate decided by the expert matched with the position of the infiltrate of the algorithm implementation. Based on the infiltrate object result that has been extracted, the amount of the infiltrate of the test image of each lungs can be counted, then the amount of pixels and size of the infiltrate object can be known.

\section{ACKNOWLEDGMENT}

The author wish to acknowledge Putra Indonesia University for the financial support of this research.

\section{REFERENCES}

[1] T Xu, Cheng I, Long R and Mandal M, "Novel coarse-to-fine dual scale technique for tuberculosis cavity detection in chest radiographs", EURASIP Journal on Image and Video Processing, Januari 2013

[2] Ankhita, B.M, Kubakaddi S. and Bharathi S.H., "Computer Aided Diagnosis of Tuberculosis using First order Statistical approach", International Journal of Electronics \& Communication (IIJEC), Vol. 3, No. 4, pp. 22-28, April 2015

[3] Bhuvaneswari, C., Aruna P. and Loganathan D., "Classification of Lung Diseases by Image Processing Techniques Using Computed Tomography Images", International Journal of Advanced Computer Research (IJACR) Vol. 4 No. 1, ISSN: No. 2249-7277, 14 March 2014

[4] Burger W and Burge M.J, Digital Image Processing An Algorithmic Introduction using Java, New York: Springer Science Business Media, LLC, 2008

[5] Costa L.F and Cesar R.M , Shape Analysis and Claassification Theory and Practice, Florida: CRC Press LLC, 2001

[6] Le K., "A Design of A Computer-Aided Diagnostic Tool For Chest X-Ray Analysis”, International Journal of Computer Science \& Information Technology (IJCSIT), Vol. 3 No. 2, April 2011

[7] Chandrika V, Parvathi C.S and Bhaskar, "Design and Development of Pulmonary Tuberculosis Diagnosing System Using Image Processing Technique and Artificial Neural Network in Matlab", International Journal of Electronics and Communication Engineering \& Technology (IJECET) Vol. 4 No. 2, ISSN : 0976-6464, April 2013

[8] Das H and Nath A, "An Efficient Detection of Tuberculosis from Chest X-rays", International Journal of Advance Research in Computer Science and Management Studies (IJARCSMS) Vol. 5 No 3, ISSN: 2321-7782 (Online), , pp. 149-154, Mei 2015

[9] Amalorpayam G , Naik H.T, Kumari J and Suresha M, “Analysis Of Digital Images Using Morphological Operations", International Journal of Computer Science \& Information Technology (IJCSIT), Vol. 5, No. 1, pp. 145-159, February 2013

[10] Ankhita B.M, Kubakaddi S and Bharathi S.H, "Computer Aided Diagnosis of Tuberculosis using First order Statistical approach", International Journal of Electronics \& Communication (IIJEC), Vol. 3, No. 4, pp. 22-28, April 2015

[11] Chandrika V, Parvathi C.S and Bhaskar, "Multi-level Image Enhancement for Pulmonary Tuberculosis Analysis", International Journal of Science and Applied Information Technology (IJSAIT) Vol. 1 No. 4, ISSN : 2278-3083, pp. 102-106, September -October 2012

[12] Edward, C.W, Joel C.W. and Alysa M.F, Practical Radiology A Symptom - Based Approach, Philadelpia : Davis Company, 2013

[13] Gonzalez, R.C, and Woods, R.E, Digital Image Processing Second Edition, New Jersey : Pearson Prentice Hall, 2002

[14] Goyal M, "Morphological Image Processing", International Journal of Computer Science \& Technology (IJCST), Vol. 2 No.4, ISSN : 0976-8491 (Online) - ISSN : 2229-4333 (Print), Desember, pp. 161166,2011

[15] Lingayat, N.S, and Tarambale M.R., "A Computer Based Feature Etraction Of Lung Nodule in Chest X-Ray Image", International Journal of Bioscience, Biochemistry, and Bioinformatics, Vol. 3 No. 6, November 2013 